\title{
Improved prediction of body fat in healthy young Irish adults: preliminary findings from the University of Limerick (UL) Body Composition Study
}

\author{
S. Leahy, C. O’Neill, R. Sohun, C. MacDonncha and P. Jakeman \\ Faculty of Education and Health Sciences, University of Limerick, Plassey Technological Park, Limerick, \\ Republic of Ireland
}

\begin{abstract}
Accurate determination of body composition informs dietary management of disease. The UL Body Composition Study ${ }^{(1)}$ seeks to establish age- and gender-specific reference ranges for whole-body and segmental body composition based on a representative sample of the Irish population residing within the UL community. With ethical approval (ULREC 08/07) and informed written consent subjects, body composition was determined by dual-energy X-ray absorptiometry (iDXA ${ }^{\mathrm{TM}}$; GE Healthcare, Chalfont St Giles, Bucks., UK; DXA). Skinfold thickness is commonly measured in clinical and field settings for the assessment of body fat (\%BF). Using standardised procedures ${ }^{(2)}$, parallel measures of skinfold thickness at selected anatomical sites were analysed by stepwise regression to construct a skinfold-thickness prediction equation that most accurately represented $\%$ BF measured by DXA. For comparison, the current skinfold data were also fitted to the most-widely-used algorithm for estimation of $\% \mathrm{BF}$ from skinfold thickness ${ }^{(3)}$. Bland-Altman analysis was used to test assess the limit of agreement between methods.

The present paper reports on the prediction of body fat from skinfold measurement using a two-compartment model of body composition for men and women aged between 18 and 35 years (Table).

Table. Anthropometric characteristics of the subjects

\begin{tabular}{|c|c|c|c|c|c|c|c|c|}
\hline \multirow[b]{2}{*}{ Subjects } & & \multirow[b]{2}{*}{ Age (years) } & \multirow[b]{2}{*}{ Height (m) } & \multirow[b]{2}{*}{ Mass $(\mathrm{kg})$} & \multirow[b]{2}{*}{ BMI $\left(\mathrm{kg} / \mathrm{m}^{2}\right)$} & \multicolumn{3}{|c|}{$\% \mathrm{BF}$} \\
\hline & & & & & & DXA & 2009 Algorithm & 1974 Algorithm \\
\hline \multirow[t]{3}{*}{ Female ( $n$ 106) } & Mean & 22.6 & 1.66 & 63.2 & 22.9 & 29.1 & 29.1 & $23.5^{*}$ \\
\hline & & 4.4 & 0.06 & 7.7 & 2.5 & 5.7 & 5.2 & 4.8 \\
\hline & Min-max & $18-34$ & $1.52-1.83$ & 49-85.4 & $18.8-33.5$ & $18-46.5$ & $20.4-46.3$ & $13.5-35.3$ \\
\hline \multirow[t]{3}{*}{ Male (n 151) } & Mean & 21.6 & 1.80 & 79.7 & 24.5 & 17.4 & 17.3 & $11.2^{*}$ \\
\hline & $\mathrm{SD}$ & 3.2 & 0.07 & 0.7 & 2.5 & 5.5 & 5.3 & 4.3 \\
\hline & Min-max & $18-35$ & $1.66-1.95$ & $61-135$ & $18.9-39.4$ & $8.9-38.2$ & $10-35.1$ & $2.9-24.2$ \\
\hline
\end{tabular}
\end{abstract}

Min-max, minimum-maximum. Mean values were significantly different from those for DXA and 2009 algorithm: $* P<0.001$.

The sum of skinfold thicknesses ( $\Sigma 4 \mathrm{SF}$ ) measured at the tricep, supraspinatus, medial calf and bicep was found to be the best predictor of the percentage body fat measured by DXA for women $(\% \mathrm{BF}=(0.2709 * \Sigma 4 \mathrm{SF})+14.1 ; R 0.916)$ and the $\Sigma 4 \mathrm{SF}$ measured at the abdomen, tricep, anterior thigh and iliac crest for men $(\% \mathrm{BF}=(0.1965 * \Sigma 4 \mathrm{SF})+6.4 ; R 0.956)$. The limits of agreement (mean difference $\pm 2 \mathrm{SD})$ approximated to $\pm 4.4 \% \mathrm{BF}$ for women and $\pm 3.3 \% \mathrm{BF}$ for men. Comparison of $\% \mathrm{BF}$ determined from the equivalent age- and genderspecific algorithm ${ }^{(2)}$ revealed limits of agreement of +1 to $+11.5 \% \mathrm{BF}$ for men, and +0.5 to $+10.8 \% \mathrm{BF}$ for women, which would indicate that a man or woman is more likely to have their \% BF underestimated from sum of four skinfolds by the Durnin and Wormersley equation $^{(3)}$.

The greater accuracy in determining body composition from skinfold measurement presented in the present paper should aid in the dietary management of disease.

1. Faculty of Education and Health Sciences (2009) University of Limerick - Body Composition Study. www.ul.ie/bodycompositionstudy

2. Marfell-Jones M, Olds T, Stewart A et al. (2006) International Standards for Anthropometric Assessment. Potchefstroom, South Africa: ISAK

3. Durnin JVGA \& Wormersley J (1974) Br J Nutr 32, 77-97. 